\title{
ESTUDOS DE IMPACTO AMBIENTAL - EIA ALGUMAS CONSIDERAÇÕES
}

KLARA ANNA KAISER MORI

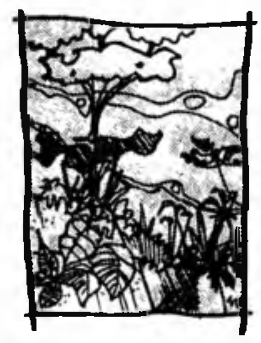

A obrigatoriedade, instituída através da Resolução n. 001/86 do Conselho Nacional do Meio Ambiente CONAMA, da apresentação de Estudos de Impacto Ambiental para projetos de empreendimentos de médio e grande portes colocou para a sociedade brasileira uma dimensão inusitada daqueles projetos, qual seja, sua relevância na dinâmica de transformações do espaço, e, conseqüentemente, da qualidade de vida. E o desenvolvimento dos EIA, já pelo simples fato de trazerem à tona questões dessa natureza, mas sobretudo por levarem à inserção dos planos e projetos de ordem físico-territorial em quadros analíticos mais abrangentes que aqueles referentes a seu objetivo imediato, permitiu, de fato, a revisão de muitos procedimentos rotineiros, imediatistas, e a reformulação de muitas soluções técnicas pobres. Basta pensar aqui nas possibilidades oferecidas pelo mero conhecimento do sítio físico de uma obra, com a gama de sugestões que possa oferecer para a formulação de novos partidos de organização, de implantação, de concepção formal, ou as contribuições que a simples contextualização de um empreendimento possa dar no sentido de uma melhor adequação a sua função. (Por exemplo, conduzindo uma via turística de forma a preservar e potencializar a paisagem de seu entorno. Exemplo esse que embora possa parecer óbvio hoje, não o era ainda recentemente, como atesta, entre tantos outros, o traçado e execução da estrada litorânea Rio-Santos, realizado na década de 70 .)

No entanto, se os EIA contribuíram para ressaltar a importância de considerações de ordem ambiental na concepção, elaboração e implantação de projetos, sua prática causou, ao mesmo tempo, um grave efeito reverso. Devido à base conceitual em que se apóia a legislação ambiental, diversos EIA culminaram em virtuais impasses. Conseqüentemente, por constituírem um crivo legal nos processos de aprovação de um conjunto amplo de empreendimentos, tumultuaram ainda mais uma área já há muito tempo problemática no país: os critérios de validação das decisões técnicas. Ou, em outras palavras, o estabelecimento daqueles vínculos significativos entre os objetivos, metas, políticas e os projetos, por intermédio dos quais estes últimos possam ganhar sentido, ou serem rejeitados. 
Algumas dessas dificuldades já se manifestaram desde a elaboração dos primeiros EIA, voltados a projetos localizados em áreas relativamente despovoadas, inseridas num meio 'natural' Mas os problemas se avolumaram, de fato, à medida em que mais e mais Estudos de Impacto se voltavam a projetos no ambiente urbano, ressaltando, e às vezes levando aos limites do absurdo, as contradições de sua fundamentação teórica.

São os problemas encontrados no processo de desenvolvimento desses EIA urbanos que motivaram as considerações a seguir. Como dito acima, de forma alguma por lhes serem exclusivos, até mesmo porque a rigor nem há sentido em se fazer, no contexto econômico-social presente, tal distinção entre áreas urbanas e e não urbanas, ou 'naturais'. Mesmo a área a mais natural possível, uma vez que se lhe atribuiu uma função, passa a se inserir no espaço produtivo do país ${ }^{1}$ A escolha se deve, simplesmente, à maior facilidade de se evidenciar, por seu intermédio, as contradições e inconsistências do quadro conceitual em que se fundamenta, hoje, o estudo ambiental.

\section{SOCIEDADE E MEIO AMBIENTE}

O conceito básico relativo aos Estudos de Impacto Ambiental é aquele referente a seu objeto, o Meio Ambiente. De acordo com a legislação, este objeto se define da forma que se segue:

Meio Ambiente: o conjunto de condições, leis, influências e interações de ordem física, química e biológica, que permite, abriga e rege a vida em todas as suas formas ${ }^{2}$.

Ora, embora se possa assumir que, em última instância são de fato, as leis, influências e interações de ordem física, química e biológica que regem a vida de qualquer ser, a tentativa de aplicação deste conceito à vida social mostra de imediato seu caráter limitador. Isto porque na vida das sociedades este conjunto de fatores sempre é enquadrado nos contornos da organização social, de forma que é sempre e necessariamente segundo os valores, parâmetros, possibilidades e limitações específicos de uma dada sociedade que aquele conjunto de leis, interaçōes e influências acima referido atua ${ }^{3}$. Reduzir a vida dos homens a uma resultante aleatória da conjugação de referidos fatores, tal como aparece na definição acima citada significa, portanto, eliminar sua característica fundamental: a intencionalidade e elaboração que marcam sua organização social.

A importância dessa questão reside, para os efeitos da realização dos EIA, nos seus desdobramentos referentes ao que venha a ser considerado Impacto Ambi- 
ental. O documento que orienta a feitura e apresentação destes estudos, adotando a definição do Conselho Nacional do Meio Ambiente, dá seus contornos assim:

Impacto Ambiental: qualquer alteração das propriedades físicas, químicas e biológicas do meio ambiente, causado por qualquer forma de matéria ou energia resultante das atividades humanas que, direta ou indiretamente, afetem:

I - saúde, a segurança e o bem-estar da população;

II - as atividades sociais e econômicas;

III a biota;

IV as condições estéticas e sanitárias do meio ambiente;

V - a qualidade dos recursos ambientais ${ }^{4}$

Assim, da mesma forma que pela omissão do papel da sociedade na determinação do meio ambiente, não há a quem atribuir a responsabilidade pelas condições vigentes de saúde, de segurança, de bem-estar, ou de suas qualidades estéticas ou sanitárias (seriam leis físicas que as teriam produzido?), na definição acima, coerente mas equivocadamente, a sociedade tampouco é tratada como responsável pela transformação daquelas condições. Ausente na sua criação, agora comparece como vítima potencial dos Impactos Ambientais - que resultariam de 'atividades humanas' não melhor delineadas.

Da dissociação de ordem teórica, operada por meio destes conceitos conjugados de Meio Ambiente e de Impacto Ambiental, deriva, na prática de desenvolvimento dos EIA, uma dissociação similar, onde às 'atividades humanas' (aquelas potencialmente agressoras do Meio Ambiente) corresponde o projeto do empreendimento em apreço; contraposto a um pano de fundo essencialmente estático e equilibrado do 'quadro ambiental' $E$ tanto isso é verdade que a obrigatoriedade de realização dos EIA se aplica explicitamente a "atividades modificadoras do Meio Ambiente"5. Quais não a seriam?

Do ponto de vista metodológico, esta ruptura se efetiva, nos EIA, nos seus dois capítulos centrais: o Diagnóstico ambiental da área de influência, e a Análise dos impactos ambientais. Em ambos, esse resultado é obtido através de vários expedientes, contribuindo isoladamente, e em seu conjunto, para que as relações entre a sociedade e seu espaço se tornem opacas (indo da indiferença, da gratuidade e da ignorância à agressividade inconsequiente). 
Assim, no Diagnóstico ressalta, antes de tudo, o fato de que para os EIA o empreendimento analisado constitui um elemento estranho ao espaço a que se destina. sem nenhum vínculo com o mesmo, nada tendo a ver com suas necessidades. De outro lado, o próprio enfoque dado ao empreendimento é deformador, uma vez que seu único aspecto de relevância é a medida em que afeta ou impacta o ambiente (= lesa, altera, entra em choque ou colisão com o mesmo). E, por último, observa-se, seguindo o roteiro, a desintegração do próprio quadro ambiental em seus assim chamados 'fatores constitutivos'; inviabilizando de vez, através da separação entre os homens e o espaço por eles apropriado, qualquer possibilidade de apreensão de um processo real.

A dissociação do Meio Ambiente em 'meios' físico, biológico e antrópico objetiva uma análise isolada de cada uma destas entidades, visando fornecer um quadro abrangente de suas características próprias. Isso, como se atividades antrópicas pudessem existir no vácuo, ou como se o meio físico ou o meio biológico pudessem ser caracterizados de forma isenta de necessidades e de valores sociais, que, embora sempre em transformação, constituem uma condição imprescindível para a reflexão ou a formulação de qualquer juízo da sociedade sobre seu espaço. E convém frisar que o fato de que em um segundo momento do diagnóstico ambiental se propõe o estudo da interação entre esses fatores ambientais $^{6}$ não elimina, ao contrário, ratifica a dissociação assinalada, por não passar de um simulacro: ela não poderá jamais recuperar a percepção da dinâmica de transformação do todo que a separação prévia ocultou.

O roteiro segue com a Análise dos Impactos Ambientais do projeto em relação a cada um dos fatores ambientais (agora de novo comparecendo separados). A identificação, previsão de magnitude e interpretação da importância de cada um dos impactos torna-se, a essa altura, um exercício praticamente inviável, pois, na ausência de um referencial que os norteie, é impossível estabelecer critérios de valoração entre elementos impactantes distintos (diretos e indiretos, benéficos, adversos, etc.) aplicados sobre fatores ambientais distintos (físicos, biológicos e antrópicos), e ainda referidos a bases físicas distintas (uma vez que a cada impacto são associados contornos específicos, correspondentes aos de sua incidência) ${ }^{7}$

Assim, a eliminação do referencial social do âmbito do estudo leva, de fato, os EIA ao beco sem saída a que se referiu no início: a pulverização dos critérios segundo os quais um projeto possa de fato ser validado ou invalidado. Esta a dificuldade cuja eliminação passa necessariamente pela reformulação do quadro conceitual em que se assenta hoje sua metodologia. 


\section{O ESTUDO DAS TRANSFORMAÇŌES DO ESPAÇO}

Ao longo das páginas precedentes uma questão de fundo acompanhou todas as observações, discussões e críticas, e que de certa forma constitui o próprio cerne deste estudo: quais os critérios em que se pode apoiar a análise de um projeto, ou, em outras palavras: como indagar corretamente do por quê das transformações, qual o propósito, a que vêm, e o que rege as mudanças ambientais? E, uma vez rejeitada a forma simplista de abordá-las como mero fator de distúrbio de um equilíbrio existente, efeito logrado por intermédio da sequiência de dissociações que vínhamos acompanhando, impõe-se a necessidade de traçar novos contornos para a questão.

A mudança de postura deve ser radical, antes de tudo dando nome à mola que impulsiona os movimentos envolvidos no estudo, tanto aos fatores soltos, disformes, ou algo inconseqüente que parecem caracterizar as 'atividades humanas' (que aparentemente nada criam, só geram impactos); como as atividades econômicas, práticas produtivas, dinâmica social, etc., arrolados no campo oposto do 'quadro ambiental', por sua vez lembrando um mero mecanismo posto em funcionamento não se sabe por quê. Essa opacidade no trato da questão não é, no entanto, gratuita - visa ocultar que está se falando de interesses em jogo na sociedade. Interesses esses opostos de múltiplas formas, dada sua estruturação em classes; e que por sua vez redundam em forças também divergentes, e orientadas tanto no sentido de se lograr transformações, quanto no sentido da manutenção do status-quo.

Assumir esses movimentos (ou essas paralisações), enquanto motivados por interesses diversos significa assumir também o fato de implicarem em conseqüentes ganhos e perdas, aqui outra vez de forma diversa do referencial conceitual dos EIA, para o qual o quadro de equilíbrio (o não-movimento, a não-transformação) aparenta sempre as tonalidades róseas da preservação de valores (antrópicos, ambientais, sociais, culturais, relacionais, e outros); enquanto o rompimento deste quadro: as mudanças se caracterizam sempre com conotações negativas.

Mas, voltando aos ganhos e perdas, o que importa reter na passagem é que precisamente o fato que tanto as mudanças, como seu bloqueio estejam imbricados num mesmo (e único) processo - englobando em cada movimento realizado ou frustrado os interesses, os valores, os objetivos da sociedade naquele momento, com todas as suas contradições é que torna vagas as aproximações que pretendem avaliá-los isoladamente: quadro ambiental estável de um lado, mudanças de outro; equilíbrio social daqui e desestabilização de lá; interesses locais versus agressões de fora, etc. 
Embora com essas colocações ainda não se tenha respondido à questão lançada, qual seja, o critério de qualificação ou validação de projetos, um passo foi dado no sentido dessa aproximação. A rejeição dos procedimentos acima ajudou a delinear melhor tanto a natureza quanto o âmbito das indagações a serem feitas; seu território é a análise crítica do processo social. A seguir deverá vir a instrumentação que viabilize esta análise, ou, de forma mais concreta e específica, a revisão e reformulação daqueles conceitos-chave dos EIA com o auxílio dos quais se possa dar conta da abordagem que se propõe.

De acordo com o que já foi visto, uma vez que o conceito de Meio Ambiente subjacente aos EIA mais oculta que revela os fatores determinantes do quadro ambiental, sua utilização constituía, naqueles estudos, o trampolim para a transposição da análise para as esferas abstratas das "leis que regem a vida". Assim, explicitando a proposta que já permeou as críticas até agora feitas, impõe-se, antes de tudo, sua substituição pelo conceito de Espaço. Este, ao incorporar em seu conteúdo precisamente o processo através do qual o território é apropriado pela sociedade, confere-lhe não só concreção, mas também uma dimensão histórica ${ }^{8}$.

Um segundo passo, decorrente do anterior, é o de se incorporar nos EIA uma característica inerente ao espaço sua contínua transformação. De fato, o suposto equilíbrio do quadro ambiental (que não existindo nem na Natureza, com muito mais razão inexiste no âmbito social) não pode constituir o ponto de partida do estudo que se propõe, uma vez que em seu esteio qualquer projeto ganha, automaticamente, uma conotação negativa, por implicar na perda de algumas características daquele quadro. Transformação, no entanto, sempre implica em alguma perda, e sua única alternativa (ainda assim fictícia) seria a opção pela estagnação, o congelamento de tudo tal como está. Por isso que impactos - enquanto fatores de mudança - não podem constituir em si critérios de avaliação de um projeto; o foco das atenções devendo se deslocar para sua qualificação: tanto a diretriz, o nível e a abrangência das transformações, como sua pertinência e oportunidade, num dado momento considerado.

Das mudanças de postura acima propostas derivam alterações substanciais na metodologia de desenvolvimento dos EIA, requerendo a reformulação de seu roteiro. Sem pretensão de esboçar sequer as diretrizes de um novo encaminhamento desses estudos, gostaria apenas, à guisa de conclusão, apontar algumas das consequiências mais imediatas do enfoque teórico adotado.

A primeira e mais evidente se liga à própria caracterização dos empreendimentos em estudo. Estes, uma vez que deixam de constituir propostas de intervenção 
soltas no tempo e no espaço, deverão ter seu significado vinculado a políticas mais amplas. Como expressão dos movimentos de transformação requeridos pela sociedade, são essas políticas que constituem a base de referência às quais os diversos projetos deverão se ajustar, e perante as quais serão validados ou não.

Cabe aqui uma breve referência à elaboração de alternativas ao projeto (tecnológicas e locacionais) - enquanto etapa obrigatória do desenvolvimento de EIAs: a questão se vincula diretamente com aquela da caracterização dos empreendimentos, pois qualquer alternativa só se constitui efetivamente como tal desde que represente uma solução compatível com os parâmetros da transformação ali considerados ${ }^{9}$

A avaliação de um projeto se faz, portanto, segundo toda a riqueza das interconexões do projeto com os diversos determinantes da qualidade de vida da sociedade. De acordo com isso, suas alternativas serão analisadas não como meras soluções técnicas implicando em relação de custos e retornos financeiros diversos, mas cujos custos e retornos econômico-sociais, e, portanto, também culturais, estéticos, ambientais, etc. constituam simultaneamente o critério válido para sua adoção ou rejeição.

Há também a necessidade de se redefinir os contornos teóricos do que venha a ser a área de influência de um empreendimento ou seja, o delineamento de sua abrangência ou alcance enquanto projeto. A definição dessa área segundo o atual roteiro se dá em duas etapas: a primeira, distinguindo entre duas ordens de grandeza do alcance dos impactos, gerando respectivamente as áreas de influência indireta e direta - procedimento esse que objetiva a distinção entre seus efeitos mais abrangentes (não se sabe porque considerados indiretos) e os de ordem próxima, ou local (considerados os impactos propriamente ditos). Numa segunda etapa, procede-se a uma delimitação das áreas de incidência dos impactos 'diretos' (de escala local) dentro dos contornos da área de influência direta, impacto a impacto, redundando, enfim, no esfacelamento da esfera de ação do projeto em inúmeras porções estanques do território.

Como já se comentou, esses procedimentos conduzem à própria dissolução do objeto de estudo ${ }^{10}$, fazendo com que se frustrem quaisquer esforços de se introduzir critérios qualitativos nos procedimentos de avaliação do empreendimento. De fato: um projeto não pode ser aprovado em suas proposições gerais e reprovado nas particulares (ou seus efeitos considerados positivos na escala global e revelando-se apenas na esfera da área de influência 'direta' os problemas por ele acarretados), como parece sugerir a referida divisão. Um projeto constitui um processo, cujas formulações se ancoram simultaneamente no geral e no local, e 
é em sua totalidade que se configurará como uma alternativa (válida ou não) para se obter o padrão de transformações que o justifique enquanto projeto, simultaneamente em todos os seus níveis de abrangência. e com a totalidade de seus efeitos, desde o mais amplo ao mais restrito e local.

\section{CONCLUSŌES}

Referido a processos de intervenção espacial, a forma de concepção das áreas de influência do empreendimento, tal como se depreende da metodologia de elaboração dos EIA, se mostra espúrio, pois, embora propostos para auxiliar na avaliação do alcance e dos efeitos daquele empreendimento, o sistema de recortes territoriais em que implica (independentemente da forma de sua classificação, segundo tipo, intensidade, ou alcance da transformação), culmina necessariamente no falseamento da própria natureza do processo de transformação que sempre se refere à totalidade do espaço. (Fato esse que não impede, de forma alguma, a possibilidade de se debruçar sobre as manifestações particulares das transformações do espaço na escala que se queira; o que deve ficar claro apenas é que tais manifestações, embora derivadas do empreendimento, não servem, isoladamente, nem para qualificá-la ou desqualificá-la, e nem sua somatória será equivalente à medida dos impactos daquele.)

E, por último. uma referência apenas a um aspecto que constitui parte substancial dos EIA, qual seja, a identificação, descrição, medição, ponderação, controle e mitigação do efeito de impactos negativos. Sem nenhuma referência a nenhum texto legal, tudo se passa nos trechos correspondentes do roteiro como se o país fosse absolutamente destituído de qualquer legislação, seja referente ao meio ambiente, a obras, a normas de aprovação de projetos; como se não houvesse uma $A B N T$, nem a regulamentação de processos de desapropriação, ou o controle dos níveis de ruídos ou de poluição atmosférica. Justificar essa atitude através do argumento de que tais leis não sejam obedecidas não terá, nesse contexto, a mínima pertinência. A postura assumida pode indicar, pelo contrário, uma brecha para se ampliar (calcado nos efetivos descalabros ambientais a que se assiste continuamente) a esfera de procedimentos arbitrários, com poder de veto sobre processos e projetos.

Seria desejável, pois, introduzir, nos EIA, a noção de parâmetros técnicos a serem atendidos, relativamente aos mais diversos aspectos dos empreendimentos, objetivando a contenção, dentro de limites aceitáveis, dos diversos transtornos por ele gerados ao longo de toda sua execução e no período de funcionamento. Além dos esforços de racionalização em que isso implica, o que se propõe aqui é 
a adoção explícita de normas já elaboradas referentes ao tema, ou. quando for o caso, o seu estabelecimento, em consonância com o padrão tecnológico vigente e aos quais os diversos projetos de empreendimento tenham que se ater.

Deve-se observar, enfim, que estes indicadores não serão nem arbitrários, nascidos apenas do desejo de melhor qualificar o ambiente vivido; nem serão absolutos ou constantes, pois se inserem na própria dinâmica de transformações do todo social. E que, embora como parâmetros de qualidade ambiental, sejam delineados em outro âmbito (histórico, social, cultural, tecnológico, estético, ou outro), eles sempre terão na esfera econômica sua principal determinante, pois, em última instância serão sempre regulados pelos custos de todo o investimento social com que se possa arcar, em dado momento histórico, para sua consecução. Assim, o patamar de qualidade de vida que representam constituirá sempre um reflexo do próprio nível de desempenho econômico da sociedade.

\section{NOTAS}

(1) Uma floresta, por exemplo, ainda que tendo permanecido intocada em toda sua complexidade biológica, e mesmo que se tenha optado por sua preservação integral e permanente, por mero efeito desta decisão já se tornou um produto de trabalho social, pois envolveu seu conhecimento, sua individuação, a emissão de um juízo, e envolverá a implementação desta medida de preservação, e a garantia de sua continuidade. Que, por sua vez, implicam não só no trabalho concreto de implantação daquela reserva, mas mesmo na manutenção do quadro institucional e da ordem política vigentes, e assim indefinidamente. Sob esse enfoque o espaço urbano só difere do nāo-urbano, ou natural pela maior densidade com que os processos sociais se dão em seu âmbito, implicando, consequientemente, em correspondente adensamento de pessoas e de artefatos (construções, redes, vias, etc.).

(2) Lei n. 6.938, de 31 de agosto de 1981, que dispõe sobre a Política Nacional de Meio Ambiente, seus fins e mecanismos de formação e aplicação, e dá outras providências. In: Legislação Básica de Interesse Metropolitano, São Paulo: Emplasa, 1985, p. 77.

(3) Aceitar o conceito de meio ambiente tal qual expresso na lei implicaria em afirmar, por exemplo, que o arroz cresce nos campos pela conjunção de fatores físicos, químicos e biológicos, e não porque se tomou a decisão de plantá-lo, para garantir a alimentação de um grupo social. Ou que a bomba cai devido à lei da gravidade. Leis físicas, químicas ou biológicas não explicam as condições econômico-sociais, as diferenciações do nível de vida, instrução, saúde, preparo técnico, nível de controle dos recursos, etc., entre os diversos grupos sociais, não revelam as formas de organização do trabalho, a evolução das condições tecnológicas, os padrões de distribuição de renda; fatores, entre outros, cujo efeito ambiental, permitindo, abrigando e regendo a vida em todas as suas formas (não só a humana mas da própria biosfera), é fundamental. Dessa forma, o papel atribuído a aquele conjunto de condicionantes de ordem física, química e biológica, embora verdadeiro, é insuficiente para o entendimento dos processos que efetivamente determinam a vida. 
(4) Artigo $1^{\circ}$ da Resolução n. 001/86 do CONAMA (In: Estudo de Impacto AmbientalEIA, Relatório de Impacto Ambiental-RIMA: Manual de Orientação. São Paulo: Govemo do Estado de São Paulo, Secretaria do Meio Ambiente, Série Manuais, 1989, p. 11.

(5) Artigo 2ㅇ da Resolução 001/86 do CONAMA (ver nota 4).

(6) "em um quadro sintético, expor as interações dos fatores ambientais..." ver p. 14 do Manual de Orientação.

(7) Ver páginas 14 a 17 do Manual. A questão que se coloca aqui é como ponderar, ou mediante que critérios avaliar positiva ou negativamente o 'impacto' causado por um fator qualquer que, por exemplo, altere a paisagem de um bairro, mas lhe garanta maior acessibilidade? Ou ainda, como decidir apoiando-se na metodologia proposta, entre os pesos respectivos da transformação das condições econômicas e sociais de uma região decorrentes da implantação de uma hidroelétrica, que, se de um lado possa resultar na elevação do padrão de vida local, de outro, implique na perda do potencial científico, cultural ou estético de uma fornação vegetal de sua área de inundação?

(8) Ver a respeito do conceito de espaço Deák, Csaba (1985): Rent Theory and the Price of Urban Land PHD Thesis, Cambridge, notadamente cap. 4. Tạmbém Mori, Klara Kaiser (1989): Contribıiçāo ao estudo da formaçāo do espaço brasileiro. São Paulo. Dissertação (Mestrado). Faculdade de Arquitetura e Urbanismo, Universidade de São Paulo.

(9) Notar que alternativas tecnológicas válidas para esse estudo comparativo deverão apresentar sempre o mesmo padrão de desempenho do projeto em análise, o mesmo alcance em seu potencial transformador. Não há sentido algum em se comparar, entre si, por exemplo, hidroelétricas de rendimento diverso, ou estabelecer comparações entre modos de transporte de capacidades distintas, ou que resultem em economias de tempo díspares.

(10) Pois um projeto não se 'aplica' sobre uma área, dando efeitos $x$ ou $y$; um projeto físico-territorial tem na transformação do espaço sua própria objetivação. 